\title{
Impact of Land Model Calibration on Coupled Land-Atmosphere Prediction
}

\author{
Joseph A. Santanello, Jr. ${ }^{1}$, Sujay V. Kumar ${ }^{2,1}$, Christa D. Peters-Lidard ${ }^{1}$, \\ Ken Harrison ${ }^{3,1}$, and Shujia Zhou ${ }^{4,1}$ \\ ${ }^{1}$ NASA-GSFC Hydrological Sciences Branch, Greenbelt, MD \\ ${ }^{2}$ Science Applications International Corporation, McLean, VA \\ ${ }^{3}$ University of Maryland, College Park, MD \\ ${ }^{4}$ Northrop Grumman Information Systems, Chantilly, VA
}

Submitted to Journal of Hydrometeorology

Summer 2012 


\section{ABSTRACT}

Land-atmosphere (L-A) interactions play a critical role in determining the diurnal evolution of both planetary boundary layer (PBL) and land surface heat and moisture budgets, as well as controlling feedbacks with clouds and precipitation that lead to the persistence of dry and wet regimes. Recent efforts to quantify the strength of L-A coupling in prediction models have produced diagnostics that integrate across both the land and PBL components of the system. In this study, we examine the impact of improved specification of land surface states, anomalies, and fluxes on coupled WRF forecasts during the summers of extreme dry (2006) and wet (2007) land surface conditions in the U.S. Southern Great Plains. The improved land initialization and surface flux parameterizations are obtained through calibration of the Noah land surface model using the new optimization and uncertainty estimation subsystem in NASA's Land Information System (LIS-OPT/UE). The impact of the calibration on the a) spinup of the land surface used as initial conditions, and b) the simulated heat and moisture states and fluxes of the coupled WRF simulations is then assessed. Changes in ambient weather and land-atmosphere coupling are evaluated along with measures of uncertainty propagation into the forecasts. In addition, the sensitivity of this approach to the period of calibration (dry, wet, average) is investigated. Results indicate that the offline calibration leads to systematic improvements in land-PBL fluxes and near-surface temperature and humidity, and in the process provide guidance on the questions of what, how, and when to calibrate land surface models for coupled model prediction. 


\section{Introduction}

Despite evidence of the importance of land-atmosphere (L-A) interactions in weather and

26

27 climate prediction (e.g. Betts 2009; Seneviratne et al. 2010), the systematic impact of land surface parameterizations on coupled mesoscale modeling has proven difficult to quantify in a robust manner. The role of the land in modulating water and energy cycling has been welldocumented in terms of land-atmosphere coupling strength and the support of hydrological anomalies and extremes such as flood and drought (van den Hurk et al. 2011; Koster et al. 2010), which includes immediate effects of the land on the temperature and humidity structure in the boundary layer, convective initiation, and mesoscale circulations (Di Giuseppe et al. 2011). In addition, the influence of soil moisture on precipitation has been under community-wide investigation in a range of studies from local (Santanello et al. 2011b) to global (Koster et al. 2004) scales. What is less understood is how specific land surface models (LSMs), parameterizations, datasets, and initialization approaches impact coupled mesoscale model predictions on diurnal timescales, and how each could be improved.

One confounding factor in quantifying LSM impact on coupled prediction lies in the varying and non-standard approaches to land surface spinup and initialization of mesoscale models. The impetus for the development of offline North American and Global Land Data Assimilation Systems NLDAS (Mitchell et al. 2004) and GLDAS (Rodell et al. 2004) was to be able to provide improved land initial conditions for numerical weather prediction and reanalysis systems. During this time, approaches to land spinup and initialization have diverged significantly among modeling groups and application. Recent studies have demonstrated the importance of a performing LSM spinups for mesoscale prediction (Chen et al. 2007; Kumar et al. 2008; Case et al. 2008, 2011; Wen et al. 2012; Di Giuseppe et al. 2011), and show marginal- 
47 to-significant improvements over cruder initialization practices based solely on coarse resolution

48 atmospheric models or reanalysis products. It still remains, though, that a great majority of

49 coupled prediction studies do not make use of rigorous spinup or initialization methods, thereby

50 limiting the potential impact of the land on those simulations before coupled integration even 51 begins.

Adding to the non-uniformity in the treatment of the land surface for coupled modeling is 53 that the complexity of LSM physics rely heavily on diverse parameter sets corresponding to soil, 54 vegetation, and other land-specific conditions and are not treated consistently across LSMs or 55 even within the same community. The accuracies of these parameters on regional scales are 56 strongly limited by their coarse resolution datasets and inability to capture local-scale

57 heterogeneity in parameters such as soil hydraulic properties. As a result, attempts have been made to calibrate parameters based on observations of land surface conditions in order to 59 ultimately improve prediction of state variables such as soil moisture (Santanello et al. 2007;

60 Harrison et al. 2012). To date, LSM calibrations have been typically performed offline

61 (uncoupled) and evaluated in terms of offline or 1-D (single-column) model predictions, and

62 have shown promise in improving state and flux prediction based on an array of observed 63 variables (Liu et al. 2003, 2004, 2005; Santanello et al. 2007; Peters-Lidard et al. 2008). The 64 results of these calibration studies are highly specific to the model, resolution, parameter set, and 65 region, however, so applicability and transferability to other offline or coupled models is 66 strongly limited (Hogue et al. 2005).

67 Unifying the LSM spinup and calibration issues is the fact that, in essence, the 68 atmospheric component of a coupled model is connected to the land solely through the fluxes. 69 As a result, the atmosphere only responds and is sensitive to the turbulent (sensible, latent heat 
and shear stress or momentum flux) and radiative fluxes coming from the land surface at each

71 timestep. From an atmospheric perspective, all the specificity and complexity of an LSM,

72 including its parameters and the spinup approach, are hidden during the execution of a coupled

73 simulation. A key question can therefore be asked: 'What is the potential impact of providing

74 'optimal' fluxes from the land surface to an atmospheric model versus those generated from

75 default or coarse resolution initialization approaches?' The answer would provide insight as to

76 the first-order influence of the land surface on accurate prediction of ambient weather (e.g.

77 temperature, humidity, precipitation) as well as the behavior of particular scheme components

78 (e.g. planetary boundary layer (PBL) height, convective initiation) in response to the optimal

79 partitioning of surface fluxes. It would also provide a methodology to control for the inter and

80 intra-LSM variability in spinup and parameterization approaches by focusing solely on providing

81 the best lower boundary condition to the coupled system.

82 In this study, we address these questions using NASA's Land Information System (LIS;

83 Kumar et al. 2006; Peters-Lidard et al. 2007). LIS supports a suite of LSMs under the

84 generalized modeling framework and facilitates the ability to utilize diverse and high-resolution

85 input data and data assimilation from local to global scales. The sensitivity of land surface

86 spinups to methods and forcing data has already been addressed under this framework (Rodell et

87 al. 2005; Kato et al. 2007). The recently developed LIS optimization and uncertainty estimation

88 subsystem (LIS-OPT/UE) provides the ability to calibrate the LSM parameters (Kumar et al.

89 2012) and evaluate the impact of parameter uncertainties on LSM outputs (Harrison et al. 2012).

90 Finally, the coupling of LIS and the Weather Research and Forecasting model (WRF-ARW;

91 Skamarock et al. 2005) has been demonstrated in a number of land-atmosphere coupling studies 
92 (Santanello et al. 2009; 2011a, 2012). For these reasons, LIS is an ideal platform from which to 93 quantify the impact of LSM calibrations on coupled mesoscale prediction.

The focus of these experiments will be on LSM calibration over a range of surface

95 conditions (dry to wet) in the U. S. Southern Great Plains (SGP) where the land is known to have

96 a strong modulating impact on the atmosphere (Koster et al. 2004; Dirmeyer et al. 2006). In the

97 process, these experiments will shed light on the following issues: 1) what to calibrate, 2) how

98 to calibrate, and 3) when to calibrate. LIS-WRF will then be evaluated using coupling

99 diagnostics already developed to simultaneously assess the land-PBL system as a whole in terms

100 of water and energy cycling. Section 2 of this paper provides some background on recent land

101 model calibration and spinup studies, as well as the coupling diagnostics developed to assess the

102 land-PBL system. The model, LIS optimization and uncertainty subsystems (LIS-OPT/UE), and

103 experimental design are then described in Section 3. Results are presented in Section 4, with

104 discussion and conclusions on the role of the land surface in coupled prediction following in

105 Section 5.

106 2. Background

107 a. LSM Spinup

108 Because in-situ and remotely sensed observations of soil temperature and moisture states

109 or fluxes are not available at the resolution of a mesoscale model grid (horizontally or vertically),

110 LSMs are used to produce flux and state estimates based on sound physics and constrained by

111 forcing (based on traditional atmospheric meteorological data such as precipitation) and

112 parameter data (based on static maps of vegetation and soil properties at high spatial resolutions).

113 The practice of long-term spinup of offline LSMs to equilibrate soil moisture and temperature

114 states has been in place for some time. Rodell et al. (2005) looked specifically at the sensitivity 
115 (and in turn, requirements) of equilibration to the length of the spinup run, which was found to

116 vary based on climate regime (e.g. cold and dry regions tend to take longer to equilibrate than

117 warm and moist locales) and soil type. They found that spinup time is typically more than 1

118 year, but no more than 3-4 years is required for most locations and conditions.

120 atmospheric forcing, and vegetation conditions (Yang et al. 1995; Chen and Mitchell 1999;

121 Cosgrove et al. 2003; de Goncalves et al. 2006). Overall, LSMs use either manual or automated

122 approaches to spinup based on reaching a minimum threshold of memory to the initial condition

123 of the run (which can range from horizontally-uniform to climatologically-distributed). The

124 particular threshold values are rather arbitrary, however, and have produced spinup times varying

125 from a few weeks to over a decade in different studies. Also a factor is whether forcing data is

126 available to run an offline LSM for the period leading up to the coupled simulation of interest, or

127 whether cyclical data from a single annual cycle must be used to equilibrate the states (e.g.

128 Cosgrove et al. 2003). For these reasons, the overall practice of spinup for coupled initialization

129 has typically been inconsistent, leaving unanswered the question of the overall impact of LSM

130 spinup on mesoscale prediction.

Recent case studies have been able to shed more light on this question, and, while limited

132 in a quantitative assessment, do indicate specific impacts and improvements in coupled models

133 as a result of improved specification of the land initial condition. Using LIS and LIS-WRF

134 (described in Section 3), Kumar et al. (2008) found significant differences in prediction of

135 fluxes, boundary layer structure, and temperature and humidity versus using default WRF

136 initialization. Their studies also revealed improvements in precipitation forecasts using LIS-

137 WRF due solely to the higher-resolution soil states from a long-term spinup run using LIS. 
Following this work, Case et al. (2008) used LIS to show that spun-up initial conditions

in LIS-WRF led to improved sea-breeze circulation and 2-meter temperature forecasts over Florida, particularly due to drier and more accurate soil moisture conditions generated by a 2year spinup. Case et al. (2011) also investigated the impact of a LIS spinup on summertime precipitation simulated by LIS-WRF over the southeastern United States. They found that the near-surface soil moisture was improved, and that there was measureable impact and improvement of the spinup on the coupled near-surface and PBL conditions relative to that using the default land initialization via WRF. Small improvements were also seen in hourly precipitation forecasts that were initialized with a LIS spinup, but impact was limited due to the dominance of the atmospheric schemes in controlling these types of airmass-generated events.

In a similar vein to LIS, the High-Resolution Land Data Assimilation System (HRLDAS, Chen et al. 2007) was developed to provide improved land initialization for WRF simulations. Holt et al. (2006) and others have likewise demonstrated a large potential impact on coupled forecasts from using high-resolution (and assumed to be improved) representation of soil states and fluxes. They also show how the combined use of a spinup approach and mesoscale modeling can be used to simultaneously test and develop new LSM physics and parameterizations by evaluating both the impact on offline spinups and the coupled forecast. Trier et al. (2008, 2011) also used HRLDAS and WRF to show that the initial soil moisture for a coupled forecast is significantly more important than the evolution of soil moisture during a 1-2 week simulation. They also showed that sensitivity to the choice of LSM complexity could be minimized by calibrating the initial soil condition.

Using a different combination of land surface and atmospheric models, Di Giuseppe et al. (2011) analyzed three approaches used for initializing soils for mesoscale modeling. Their 
161 intercomparison of soil initialization using a) downscaling from a coarse resolution global parent

162 model, b) results from a previous mesoscale coupled run, and c) nudging of soil moisture based

163 on screen-level temperature observations indicate strongly that consistency in the physics and

164 configuration between the offline and coupled models is paramount when choosing a source for

165 initial values of soil moisture and temperature profiles. Therefore, the approach of using a

166 previous run (i.e. spinup) of the same LSM to initialize the coupled forecast produced the best

167 results, while the other two approaches were discouraged in practice. They also highlighted the

168 importance of the soil temperature profile initialization (typically ignored in previous studies).

The impact of improved initialization of land surface states in WRF short-term prediction

170 was also demonstrated by Wen et al. (2012). Although a spinup was not used, they updated the

171 initial condition with in-situ observations of soil moisture and temperature and new land cover

172 data measured from satellite and found significant impacts on all coupled components of the

173 WRF simulation across a heterogeneous (dry/wet) region, including the atmospheric circulation

174 enhanced by the surface conditions.

175 Overall, these studies have demonstrated an impact of LSM spinups on coupled

176 prediction and are focused on short-term (diurnal) forecasts over mesoscale domains (1-10 km

177 horizontal resolution), as will be the case performed here using LIS-WRF. Further, the

178 consistent use of the same model and configuration to generate the soil initial conditions in the

179 spinup and the coupled run is specifically what LIS and LIS-WRF has been designed for as a

180 testbed, and follows with what these studies have suggested as best practice for maximizing the

181 positive impact of the land on coupled prediction.

182 b. Calibration of Offline and Coupled LSMs 
As mentioned, the physics of LSMs are highly dependent on specification of a large

number of parameter values representing soil, vegetation, and other surface conditions. To simplify things, lookup tables are commonly associated to a particular soil or vegetation type that relates a number of parameters to each classification. Lookup tables are only as accurate as the available soil or vegetation information, however, and attempt to provide a representative value of each parameter for each soil or vegetation type. High-resolution maps that accurately capture the observed heterogeneity in parameter values are difficult to obtain on the scales of land surface and mesoscale models (particularly for regions outside the U. S. and on global scales), and there is little flexibility between soil or vegetation classes (e.g. for mixed crops or soil types). This can be a problem, particularly for soils where larger differences in soil parameters have been observed within a soil type than between types (Feddes et al. 1993; Soet and Stricker 2003; Gutmann and Small 2005; Santanello et al. 2007).

In order to combat these limitations, numerous attempts have been made to calibrate (or 'optimize') LSM parameters using observations of state variables such as soil moisture and surface temperature as constraints (Gupta et al. 1999; Hess 2001; Hogue et al. 2005; Liu et al. 2003, 2004, 2005; Santanello et al. 2007; Peters-Lidard et al. 2008; Harrison et al. 2012). Such approaches can improve matches of state variables to observations during the calibration period (and beyond), and in the process address LSM systematic biases. However, it remains difficult to derive parameter information that could be evaluated independently as most studies have focused on techniques that derive large sets of 'effective’ parameters. Such studies also require a great deal of computational time and limit assessment of larger-scale applicability, and as a result little has been gained in terms of quantifying the effectiveness of calibrated parameters in improving coupled simulations. 
For example, Hogue et al. (2005) investigated the transferability of large calibrated parameter sets in an offline LSM across varying surface conditions and time periods. They conclude that optimization should be site-specific for best results, and should be recalibrated for 209 changes in seasons or over longer time intervals even if the surface and climatic features of the region remain the same. This suggests that if a spinup is to be used to initialize a coupled model,

211 the calibration performed offline needs to be tailored (e.g. domain, resolution, LSM) specifically

212 for the experiment of interest. In turn, this supports the idea that a testbed such as LIS and LIS-

213 WRF is ideal for such investigations.

214 Liu et al. (2003) extended parameter estimation to coupled systems by examining the 215 pathways by which limitations in the LSM physics impact both offline and 1-D (single-column) 216 model simulations. Their results show that offline calibration is well-constrained due to the 217 realistic forcing applied and is able to identify and correct deficiencies in evaporative physics, 218 but in coupled mode some parameter sets acted to amplify flux errors due to occurrence of land219 atmosphere feedbacks. Liu et al. (2004) and (2005) then included atmospheric parameters in the 220 calibration, and highlight the computational difficulty in calibrating large parameter sets in 221 coupled models (which has precluded the calibration of a full 3-D mesoscale model to date). As 222 a result, they suggest a stepwise procedure of offline before coupled calibration as an alternative.

223 Overall, their results found that calibrated parameter values are particularly sensitive to the 224 surface latent heat flux as the lower boundary condition, and all simulations were found to be 225 highly sensitive to the initial soil moisture value (prescribed uniformly in their study rather than 226 spun up), stressing the importance of an accurate LSM spinup for coupled simulations. Overall, these studies have highlighted that the land initialization for coupled models is 228 important, and that the methodology of an offline spinup with calibrated parameters shows 
229 promise in providing the most accurate initial condition consistent with best surface physics and

230 parameterizations. Performing fully coupled (3-D) land surface and atmospheric parameter

231 calibration remains a daunting task, but we are now in a position to quantify the impact of an

232 optimal and physically meaningful LSM spinup for coupled prediction models.

233

234

235

236

237

238

239

240

241

242

243

244

245

246

247

248

249

250

251

252

\section{c. Evaluation of Land-Atmosphere Coupling}

The quantification of land-atmosphere interactions in coupled models is a complex task that involves a great number of processes and feedbacks. For example, in terms of accurately representing the relationship between soil moisture $(S M)$ and precipitation $(P)$ in coupled models, a full understanding will only come by careful examination and quantification of a series of interactions and feedbacks (i.e. 'links in the chain') that can be summarized as follows (from Santanello et al. 2011a):

$$
\Delta S M \rightarrow \triangle E F_{\text {sm }} \rightarrow \Delta P B L \rightarrow \triangle E N T \rightarrow \Delta E F_{\text {atm }} \rightarrow \Delta P / \text { Clouds }
$$

(a)

(b)

(c)

(d)

where $E F$ is the evaporative fraction, defined as

$$
E F=\frac{Q l e_{s f c}}{Q h_{s f c}+Q l e_{s f c}}
$$

and is a function of the sensible $\left(Q h_{s f c}\right)$ and latent $\left(Q l e_{s f c}\right)$ heat fluxes at the land surface. From Eq. 1, the impact of soil moisture $(\Delta S M)$ on clouds and precipitation $(\Delta P)$ is therefore dependent on the sensitivities of: a) the surface fluxes $\left(E F_{s m}\right)$ to soil moisture, b) PBL evolution to surface fluxes, c) entrainment fluxes at the PBL-top (ENT) to PBL evolution, and d) the collective feedback of the atmosphere (through the PBL) on surface fluxes $\left(E F_{a t m}\right)$ (Santanello et al. 2007; van Heerwaarden et al. 2009). As a result, there are numerous pathways composed of positive and negative feedback loops in this chain, including the influence of additional inherent and external factors (e.g. canopy interception, large-scale convergence). 
The initial communication between the land and atmosphere occurs on local scales, and 254 therefore a community effort has been launched to diagnose and quantify local L-A coupling in 255 coupled models, called 'LoCo' (Hurk and Blythe 2008; Santanello et al. 2009, Santanello et al. 256 2011b). The realm of LoCo has been defined by GLASS as "The temporal and spatial scale of 257 all land-surface related processes that have a direct influence on the state of the PBL".

258 Therefore, the fundamental processes that fall into this realm correspond directly to the question 259 of the role of offline LSM spinup on coupled mesoscale prediction. This research is a core 260 component of the Global Energy and Water Cycle Study (GEWEX) Land Atmosphere System 261 Study (GLASS; Hurk et al. 2011), which coordinates community working groups and 262 intercomparison studies related to offline and coupled land surface modeling. A thorough review 263 of LoCo research and the related diagnostic framework can be found in Santanello et al. (2009, 264 2011a, 2011b, 2012; hereafter referred to as S09, S11a, S11b, S12).

LIS and LIS-WRF have served as a core testbed to develop and implement LoCo 266 diagnostics utilizing the range of LSM and PBL scheme options available in each. Under this 267 framework, a methodology that simultaneously addresses the components of Eq. 1 was tested by 268 S09 and extended by S11, and employs the 'mixing diagram' approach as introduced by Betts 269 (1992). This power of this diagnostic lies in its ability to exploit the co-variance of 2-meter 270 potential temperature $(\theta)$ and humidity $(q)$ to quantify the components of the LoCo process271 chain, and is based only on routine variables that can be applied to any model or observations 272 and across a range of scales. From this analysis, the full PBL budgets of heat and moisture, 273 relationship of EF to PBL height (PBLH), and the evolution of the lifting condensation level 274 (LCL) deficit (PBLH minus LCL) can be derived and used to understand the nature of and 
275 sensitivity of a particular land-PBL coupling. For a full description of this approach and

276 implementation for LoCo studies, the reader is again referred to S09 and S11a.

The LoCo approach diagnoses the land and PBL fluxes simultaneously, and therefore

278 provide the components of the full budgets of heat and moisture in the coupled system. LoCo

279 diagnostics can therefore be used to quantify the joint evolution of coupled variables, such as

280 those that showed strong sensitivities in earlier studies, but only independently (e.g. $\theta$ and $q$ in

281 the work of Trier et al. (2008)). As shown in S09 and S11a, how anomalies and/or errors in the

282 surface fluxes computed by a particular LSM-PBL coupling are then translated into the

283 atmospheric water and energy cycle can then be quantified using this approach. Differences in

284 soil moisture differences strongly impact the signatures of heat and moisture evolution and

285 diagnosis of coupling behavior. For example, results from S12 during dry/wet extremes show

286 that the choice of LSM is critical for dry regimes, but that both PBL and LSM are comparable

287 influences on the coupled behavior during wet regimes. LoCo diagnostics are therefore well-

288 suited to capture the first-order impact of land spinup and specification on the PBL and

289 atmosphere as a whole.

290 3. Model and Site Description

291 a. LIS and LIS-OPT/UE

292

NASA's Land Information System (LIS) consists of a suite of LSMs under the same

293 software framework and provides a detailed representation of land surface physics and states,

294 which can then be directly coupled to an atmospheric model. More recently, new subsystems

295 have been added to LIS that allow sophisticated optimization and uncertainty estimation (LIS-

296 OPT/UE) algorithms to be applied to the LSMs to exploit further the information content from

297 observations. The algorithms (e.g. Levenberg-Marquardt (Levenberg 1944; Marquardt 1963), 
298 Genetic Algorithm (Holland 1975), Shuffled Complex Evolution from University of Arizona

299 (Duan et al. 1993)) calibrate the model parameters to the remote sensing observations, thereby

300 enabling improved model forecasts and enhancing the efficiency of data assimilation approaches

301 (Santanello et al. 2007, Peters-Lidard et al. 2008, Kumar et al. 2012a). The uncertainty

302 estimation subsystem also includes Bayesian approaches based on Markov Chain Monte Carlo

303 (Gilks et al. 1996) to estimate the uncertainty in model parameters given calibration datasets,

304 which enables probabilistic prediction.

305 Overall, the high-performance computing infrastructure in LIS provides an advantage

306 over previous parameter estimation studies which were limited to trial and error, manual, and

307 lower-dimensional (i.e. smaller parameter sets) calibration approaches, and have been

308 demonstrated by Kumar et al. (2012) and Harrison et al. (2012) for offline spinup and data

309 assimilation applications. The evaluation of offline, coupled, and LIS-OPT/UE experiments is

310 performed using a LIS-based tool called the Land surface Verification Toolkit (LVT; Kumar et

311 al. 2012b). LVT provides a standardized platform for intercomparing model output (from LIS or

312 other sources) with observations and offers a range of statistical and benchmarking approaches.

313 b. NU-WRF

314 Derived from the Fifth-Generation NCAR/Penn State Mesoscale Model (MM5; Anthes

315 and Warner 1978), WRF-ARW has been designated as the community model for atmospheric

316 research and operational prediction and is ideal for high-resolution (e.g. 1-10 km) regional

317 simulations on the order of 1-10 days. WRF-ARW has a Eulerian mass dynamical core and

318 includes a wide array of radiation, microphysics, and PBL options as well as 2-way nesting and

319 variational data assimilation capabilities. 
Recently, work has been performed to develop a NASA-Unified WRF (NU-WRF;

321 https://modelingguru.nasa.gov/community/atmospheric/nuwrf) modeling system at NASA's

322 Goddard Space Flight Center (GSFC). NU-WRF is built upon the WRF-ARW model, and

323 incorporates and unifies NASA's unique experience and capabilities by fully integrating LIS, the

324 WRF/Chem enabled version of the Goddard Chemistry Aerosols Radiation Transport

325 (GOCART; Chin et al. 2000) model, GSFC radiation and microphysics schemes, and the

326 Goddard Satellite Data Simulation Unit (SDSU; Matsui et al. 2009) into a single modeling

327 framework. In turn, NU-WRF provides the modeling community with an observation-driven

328 integrated modeling system that represents aerosol, cloud, precipitation and land processes at 329 satellite-resolved scales.

330 The land-atmosphere coupling is a core component of NU-WRF, and has been performed 331 through the coupling of LIS and WRF by Kumar et al. (2008). The advantages of coupling LIS 332 and WRF include the ability to spin-up land surface conditions on a common grid from which to 333 initialize the regional model, flexible and high-resolution (satellite-based) soil and vegetation 334 representation, additional choices of LSMs that continue to expand in range and complexity, and 335 direct coupling of the atmospheric model to the LIS subsystems (including LIS-OPT/UE). The 336 work of S09, S11a, and S12 has demonstrated NU-WRF as a testbed for L-A interaction studies 337 and LoCo due to its land-PBL scheme flexibility and high resolution. Hereafter we refer to NU338 WRF as the coupled prediction system that includes the LIS-WRF coupling for these 339 experiments.

The continuous development and support of NU-WRF ensures that the most recent 341 versions of LIS (currently V 6.2) and WRF-ARW (currently V 3.2) are coupled and tested, and 342 are used in this study. The experiment described below are run on a single 500x500 domain at 1 
$343 \mathrm{~km}$ spatial resolution (see below), and include a 5-second timestep, GSFC microphysics,

344 longwave, and shortwave radiation, and the Monin-Obukhov surface layer scheme. The North

345 American Regional Reanalysis (NARR; Mesinger 2006) data was used for atmospheric

346 initialization and lateral boundary conditions using 3-hourly nudging, and the vertical resolution

347 of NU-WRF was specified as 43 vertical levels, with the lowest model level $24 \mathrm{~m}$ above the

348 surface.

The LSM employed in LIS for this study is the Noah LSM (Noah; Ek et al. 2003), and

350 was originally developed from the land component of the Oregon State University 1-D PBL

351 model (Troen and Mahrt, 1986). The Noah model employed in this study is Version 3.2 and is

352 identical to the version of Noah packaged in the original version of WRF-ARW Version 3.2.

353 Noah is used operationally by the National Center for Environmental Prediction as the LSM for

354 the North American Mesoscale (NAM) model and the Global Forecasting System (GFS). As

355 such, Noah is a well-supported, developed, and utilized LSM for both offline and coupled

356 applications. Particularly important for the LIS-OPT/UE calibration (see below), the soil type

357 specification in LIS is based on the STATSGO (Miller and White 1998) database over the U. S.,

358 while vegetation type is assigned based on the UMD landcover dataset (Hansen et al. 2000).

359 The PBL scheme chosen in NU-WRF is the Yonsei University (YSU; Hong et al. 2006)

360 PBL, based on non-local K theory and includes explicit treatment of entrainment and counter

361 gradient fluxes. The combination of Noah LSM and YSU PBL is a common selection in WRF,

362 and has served as the default configuration for test cases involving NU-WRF. While some

363 results suggest other PBL schemes in WRF sometimes perform better than YSU under certain

364 conditions (e.g. stable/nighttime periods), a universally-accepted hierarchy of PBL scheme usage 
365 has not been developed as of yet and it is beyond the scope of this study to engage in further

366 study of PBL and LSM scheme sensitivities (which can be seen in S12).

367 c. 2006-7 Dry/Wet Extremes

368 The SGP region has been identified as a hotspot for land-atmosphere coupling in terms of 369 the strength of interactions and impact of soil moisture anomalies on clouds and precipitation 370 (e.g. Koster et al. 2004). Because of this, and the large record of observational data from the 371 Atmospheric and Radiation Measurement testbed (ARM-SGP), S09, S11a, and S12 have focused 372 WRF studies on the SGP region to develop and test the LoCo diagnostics described in Section 373 2c. In particular, S12 looked at the extreme conditions observed during the 2006-7 period and 374 the impact on LoCo. Low anomalies of clouds and precipitation in 2006 (October-September) 375 were immediately followed by conditions of high cloudiness and rainfall in 2007, with 2006 376 being the second driest and 2007 the seventh wettest year on record. This period was followed 377 by a relatively normal summer season in 2008, with soil moisture conditions in between that of 378 the 2006 and 2007 extremes (as confirmed by ARM-SGP observations and Noah simulations). As described in S12, ideal case studies were chosen for each regime. The 14-20 July

3802006 experiment consists of a lengthy dry-down period with little synoptic disturbance in which 381 the land was free to interact and evolve with the atmosphere on primarily local scales. The case 382 study of 14-20 June 2007 focuses on a period with scattered precipitation every 1-2 days in 383 portions of the ARM-SGP domain, interspersed with brief dry-downs in which conditions were 384 clear and/or cloudy and culminating in a large mesoscale convective system (MCS) traversing 385 the domain on the final nighttime period.

386 d. Experimental Design: Default Spinups 

et al. 2012) project was used to drive the spinup simulations. Noah was run offline in LIS beginning 1 January 2003, thus producing a 3.5-4.5 year spinup prior to the start time of the 2006 and 2007 case studies. This is longer than the recommended spinup length based for similar moisture regimes (soil and precipitation), and is consistent with previous studies using

392 this LSM, location, and time period (S09, S11a, S12) in ensuring a fully-equilibrated soil 393 condition that is insensitive to the initial condition of the spinup (horizontally homogeneous in 394 this case).

Using the resultant spun-up surface fields as initial conditions for the 2006-7 case studies, NU-WRF simulations were then performed over a single high-resolution $1 \mathrm{~km}$ domain centered over Oklahoma and Kansas. Figure 1 shows the upper layer $(0-10 \mathrm{~cm})$ soil moisture values over the ARM-SGP domain as generated by Noah spinups valid at 00Z on 1 July 2006, 2007, and 2008. The advantages of using LIS for this purpose are evident in the high spatial resolution seen in Fig. 1 as a reflection of the inputs of vegetation and soil properties. Soil moisture varies significantly from dry and heterogeneous (generally < 25 percent volumetric) in 2006 to

402 extremely wet (near saturation) and more uniform conditions in 2007, with 2008 showing more 403 moderate soil moisture and heterogeneity.

404 e. Experimental Design: LIS-OPT/UE Case Studies

406 OPT/UE, and applied to a set of 29 parameters describing soil, vegetation, and general 407 characteristics in the Noah model (Table 1). The goals of calibration are to provide the best 408 possible surface fluxes for NU-WRF simulations. Therefore, the observations employed are 409 measurements of sensible (Qh), latent (Qle), and soil (Qg) heat fluxes from the ARM-SGP 
network of sites over the domain, including 6 Energy Balance Bowen Ratio (EBBR; Qh, Qle, and Qg) and 12 Eddy Correlation (ECOR; Qh and Qle only) tower locations. The GA was applied using an objective function that minimizes RMSE with no discrimination of flux type (i.e. Qh, Qle, and Qg flux observations are weighted equally). The calibration was performed over the periods of 1 May - 1 Sept of 2006, 2007, and 2008 to produce separate calibrated parameter sets for the dry, wet, and normal regimes. Having three separate calibration periods allows for the study of the impact of calibration period and varying atmospheric and land surface conditions on the calibration results.

The number of observations of Qle, Qh and Qg that used in the GA optimization are comparable, but vary slightly from 2006 (Qle: 48546, Qh: 48822, Qg: 32218) to 2007 (Qle: 37936, Qh: 39063, Qg: 30100), and to 2008 (Qle: 45767, Qh: 48353, Qg: 31344). As a result, the objective function is skewed towards the fluxes with the greater number of observations in each case and therefore is weighted more heavily towards Qh and Qle than Qg. The GA integrations use a population size of 50 and employ an elitism strategy to ensure that the current best solution is not overwritten during GA evolution, with a mutation rate of 0.005 and a recombination rate of 0.9 . The GA parameters (including the mutation and recombination rates) are chosen largely from experience and the success of the optimization simulations in Kumar et al. (2012). The algorithm was found to converge after approximately 200 generations, when the fitness of the best solution was found not to improve in the last 30 generations.

From these simulations, a unique calibrated value of each of the 29 Noah parameters was obtained at each of the 18 grid cells pertaining to the flux sites. In order to obtain calibrated values covering the full model domain, the values from each site then were grouped and averaged by common vegetation and soil types and assigned to the full domain based on the 
433 vegetation and soil classification at each grid cell. Note that Noah parameters were designated 434 into soil (15 parameters, 5 classes in the SGP domain), vegetation (11 parameters, 3 classes in 435 the SGP domain), and general (3 parameters, no classification) categories as based on their 436 functionality and most direct impact on the model physics. For example, for a soil-related 437 variable such as porosity, the calibrated values of porosity from each flux site with a 'clay' 438 classification were averaged, and then applied as the porosity value to the remainder of the 439 domain where 'clay' was also the soil type. Also, if a soil/vegetation class occurs in the domain 440 but was not represented at one of the observation sites, default table values are used. General 441 parameters are constant across the domain and do not have a classification, and therefore were 442 averaged across all the sites.

443 Using the calibrated parameters, new soil, vegetation, and general lookup tables for Noah 444 were then generated. Spinup runs (as described in the previous section for the default case) were 445 repeated using the new tables based on the 2006, 2007, and 2008 calibration results, thereby 446 producing spun-up and initial conditions that are optimized for dry, wet, and average conditions, 447 respectively, over this region. To examine the impact of calibrated spinups on coupled forecasts, 448 four targeted NU-WRF case studies were then chosen from the larger 7-day periods described 449 above, with characteristics as follows:

•14 July 2006: 24 hours, dry regime; NU-WRF test case •18-19 July 2006: 48 hours, dry regime; peak of dry-down

•16-17 June 2007: 48 hours, wet regime; limited/scattered precipitation •19-20 June 2007: 48 hours, wet regime; scattered/MCS precipitation NU-WRF was then run for each case study above using four different combinations of 455 parameter values/lookup tables, as shown in Table 2. The array of simulations was designed to 
capture the impact on NU-WRF forecasts from using a combination of a) default spinup

457 (uncalibrated) and default parameters in the coupled run (DEF), b) default spinup with calibrated

458 parameters in the coupled run (CPL), c) calibrated spinup with default parameters in the coupled

459 run (SPN), and d) calibrated spinup with calibrated parameters in the coupled run (SCP). Note

460 that the focus of the results presented here will be on the differences between the DEF (no

461 calibration) and SCP (fully calibrated) cases, but CPL and SPN offer the ability to parse out the

462 relative impacts of using optimal parameters during the spinup vs. coupled simulation period,

463 and will be included in the discussion when relevant.

464 f. Observation Data

465 The ARM-SGP program provides a long-standing record of quality-controlled surface

466 flux, meteorological, and hydrological observations along with atmospheric profiles for a

467 network of sites across the domain shown in Fig. 1. This includes co-located soil moisture, net

468 radiation, sensible, latent, and soil heat, along with co-located surface meteorology data that

469 provide the full set of variables needed to calculate the LoCo diagnostics discussed in Section 2c

470 and evaluate against model results. For the calibration experiments, ARM-SGP data was

471 collected from ECOR and EBBR towers, and the LoCo evaluation was performed using the co-

472 located surface meteorology, flux towers, and available radiosonde profile data.

\section{4. Results}

474 The performance of the offline calibration experiments will be evaluated first, followed by the 475 impact of spinup calibration and initialization on NU-WRF predictions and LoCo, the sensitivity

476 of the coupled results to the period of calibration, and concluding with the uncertainty introduced

477 into the forecasts by different parameter sets.

478 a. Offline Calibration 
Before examining the coupled cases, it is important to quantify the impact of the

480

481

482

483

484

485

486

487

488

489

490

491

492

493

494

495

496

497

498

499

500

501

calibrated parameters on the offline spinup. Figure 2 shows the flux components simulated using default and calibrated Noah parameters during the dry regime (2006) versus observations at each of the ARM-SGP sites and over the full domain. Both Qh and Qle show improvement at nearly all sites, with RMSE values reduced by up to $25.7 \mathrm{Wm}-2$ (10.5 Wm-2 on average) in Qle, and up to $45.3 \mathrm{Wm}-2$ (19.1 Wm-2 on average) in Qh. Note that the 95 percent confidence interval for the domain averages are $~ 4-7 \mathrm{Wm}-2$, so the improvements are statistically significant. The improvement due to the calibration is also clearly evident in the mean diurnal cycle behavior of Qh and Qle across all sites. Focusing on the daytime when the turbulent fluxes are large and positive, Qh matches observations almost exactly and improves over the high bias present in the default simulations. Analogously, daytime Qle increases due to calibration and matches observations more closely than when default parameters are used in Noah. The Noah model has often been shown to produce systematic over/underestimation of surface fluxes, and the GA calibration successfully improves upon the biases exhibited for the SGP and study period demonstrated here.

Qg shows more mixed results, with 5 of the 11 EBBR sites showing slight degradation after calibration, but the magnitudes for Qg are small overall and this does not present a concern for this study. The mixed results are partially a reflection of the reduced number of observations of Qg available for the GA and the heavier weighting towards Qh and Qle. In addition, phase errors in Qg are well documented (Robock et al. 2003, Reichle et al. 2010) and could possibly be corrected if joint calibration approaches including soil temperature and Qg were conducted.

Figure 3 shows the offline calibration results for the wet regime (2007), and once again Qh and Qle are improved at nearly all ARM-SGP sites (and in the case of Qh, all sites show 
502 improvement). In this calibration, Qh improvements are more modest than in 2006 (up to 25.9

503 Wm-2 and $12.3 \mathrm{Wm}-2$ on average), while Qle improvements are larger than during the dry

504 regime (up to $54.9 \mathrm{Wm}-2$ and $12.3 \mathrm{Wm}-2$ on average). Interestingly, Site E24 shows the largest

505 improvement in this case, opposite of the 2006 calibration. The mean diurnal cycles show

506 marked improvement (decrease) in daytime Qle over the default simulations, while Qh is only

507 very slightly impacted (and also decreased). This suggests an available energy bias and

508 overestimation in the offline Noah runs in 2007. Once again, Qg shows mixed results as 5 of 11

509 sites show degradation; though in this case there is a noticeable increase in Qg after calibration

510 that improves afternoon simulations, but does not impact the phase error where Qg peaks too

511 early (as in the 2006 case).

512 Overall, the largest impact and improvement due to calibration of Noah is seen in Qh in

5132006 and in Qle in 2007. Physically, this can be explained by the fact that during the dry regime,

514 Noah has a dry bias and produces too little evaporation thereby overestimating Qh. In the wet

515 regime, Noah has a wet bias and produces too much Qle (partially due to too much net

516 radiation). The LIS-OPT/UE calibration has thus adjusted the parameter values accordingly, to

517 correct for the dry bias in 2006 by increasing soil moisture and modifying the efficiency of the

518 evaporative physics in Noah (and vice-versa in 2007) that compliments the new soil moisture

519 levels to produce the optimal fluxes. These results are also consistent in that during a dry regime

520 which is water-limited, the primary adjustment in fluxes would be towards the higher magnitude

521 flux (Qh), and during a saturated regime the largest impact would be felt in Qle.

522 b. Coupled Simulations 
524 diagnostics are used to simultaneously evaluate the land (LSM) and atmospheric (PBL)

525 component evolution and interaction.

526 1) 14 JULY 2006

527

528

529

530

531

532

533

534

535

536

537

538

539

540

541

542

543

544

545

The mixing diagram analysis for the 14 July 2006 case at the ARM-SGP E4 site is shown in Fig. 4. Focusing first on the comparison of the DEF and SCP simulations, it is shown that the default Noah parameters produce the poorest simulation of heat and moisture states and fluxes in NU-WRF. Visually, the DEF curve is drier (and slightly warmer) than observed throughout the daytime period. This is improved significantly in the SCP simulation which matches closely with observed T2 and Q2 throughout. Table 3 provides error statistics of simulated versus observed T2 and Q2 co-evolution, and because mixing diagrams are in energy-space these can be represented in units of $\mathrm{J}$ kg-1 and used to describe a total RMSE and MAE of heat and moisture combined (i.e. quantifying the spatial differences between the model and observed curves in Fig. 4). These metrics confirm that the DEF run performs worst of all the simulations, while the SCP improves all aspects of the temperature and moisture states (T2 and Q2) by 15-26 percent in RMSE and 8-30 percent in bias.

The fluxes in the coupled system can be evaluated via the Bowen and entrainment ratios (as defined by S09 and in Fig. 4). As expected, SCP produces a $\beta_{\mathrm{sfc}}\left(=\mathrm{Qh}_{\mathrm{sfc}} / \mathrm{Qle}\right.$ sfc $)$ nearly identical to that observed due to the calibration to surface fluxes performed, which produced the parameters used in the SCP simulation. DEF overestimates $\beta_{\mathrm{sfc}}$, consistent with the dry bias observed in the offline spinup and the coupled T2 and Q2 results. The entrainment fluxes (as reflected by Bent) are also impacted by the LSM calibration by 15 percent and slightly closer to observations. Likewise, the heat and moisture entrainment ratios (Ale and Ah) show substantial 
546 improvement in SCP over default, where the higher Qle and lower Qh as a result of correcting

547 the dry bias at the surface produce better ratios of land to PBL fluxes.

Focusing on the remaining two simulations, CPL and SPN, indicates how calibrated

549 parameters impact coupled simulations when used in either offline spinups or the coupled run

550 only. It is first evident that SPN does well with T2 and Q2 state estimation, correcting the dry

551 bias of Noah, and producing the best overall error metrics in Table 3. The fluxes of SPN are

552 severely overcompensated, however (e.g. $\beta_{\text {sfc }}$ very low), and produce too much evaporation.

553 Because the calibrated parameters in this simulation are used only for the spinup, these results

554 indicate that the default parameters still employed in the coupled run produce too high of

555 evaporation rates for the given initial soil moisture state. The CPL simulation performs poorly

556 both in terms of T2 and Q2 (with comparable or worse metrics in Table 3 to the DEF simulation)

557 and surface and PBL fluxes, indicating that using calibrated parameters only for the coupled

558 simulation along with a default spinup does not impact or improve the coupled forecast at all.

559 These results are also consistent with those of Trier et al. (2008), who showed that initial soil

560 moisture (i.e. fluxes calibrated in SPN) has a much larger influence on forecasts than the

561 evolution of soil moisture during the coupled run (i.e. fluxes calibrated in CPL).

562 The full heat and moisture budgets of the coupled system can be derived from the mixing

563 diagram analysis and are shown in Fig. 5. The calibration of the surface fluxes to observations in

564 SCP is most evident, as is the overestimation of Qle and Qh in the SPN and CPL simulations,

565 respectively. Less impact of different calibration approaches is seen in the PBL components of

566 the budget, where all are relatively close to observed. The total budgets do, in turn, directly

567 reflect the improvement of surface fluxes in the SCP and SPN simulations. 
Another related diagnostic of the coupled system performance is the relationship of 569 evaporative fraction (EF) and PBL height (PBLH), as shown in Fig. 6. Once again, the best 570 combination of land and atmospheric behavior is exhibited by the SCP simulation, which closely 571 matches both the EF (which integrates the land surface condition) and PBLH (which integrates 572 the atmospheric response). SPN and CPL are the extremes in terms of EF and PBLH, while the 573 dry bias in the DEF simulation is evident and leads to slightly higher PBL growth. From the full suite of simulations and diagnostics in Figs. 4-6 and Table 3, it is clear that 575 offline LSM calibration can improve coupled simulation components significantly and in a 576 consistent fashion in terms of correcting a bias and the impact of that correction (e.g. soil 577 moisture) on the coupled components (e.g. T2 and Q2). It is also evident that employing 578 calibrated parameters in both the offline spinup and the coupled run is required to achieve 579 optimal improvement in coupled prediction. It is the combination of a spinup produced with 580 calibrated parameters that support a wetter initial condition along with those same parameters 581 that support lower evaporation rates in the coupled simulation that are actually compensatory. 582 Therefore, if the calibrated parameters are only used in either the spinup or coupled run, 583 significant and overreaching impacts will be seen in the prediction of coupled states and/or 584 fluxes (as seen in SPN and CPL).

585 A robust measure of the impact of LSM spinup and calibration on NU-WRF simulations 586 can be found in the performance of T2 and Q2 across the entire model domain. Figure 7 shows 587 the domain average statistics computed using the Model Evaluation Tools statistical software 588 package (MET; developed by the National Center for Atmospheric Research (NCAR): 589 www.dtcenter.org/met/users/docs/overview.php and incorporating NCEP Automated Data 590 Processing (ADP) atmospheric and surface data), and based on 214 site observations at 6-hourly 
591 intervals on 14 July 2006 which provides a true independent evaluation of the model. In

592 particular, the RMSE and Bias statistics are largely improved in SCP versus DEF and are

593 consistent in terms of lowering the dry/warm bias of the default simulation. Also plotted are the

594 results from a NU-WRF simulation that does not use LIS nor a spinup of the Noah LSM (as a

595 true 'off the shelf' WRF-default case comparison). Overall, by introducing a spinup (DEF vs.

596 WRF) there is a definite increment of improvement over a default or coarse atmospheric-based

597 initial condition (e.g. NARR in this case). Performing offline calibration for a spinup then

598 increases the accuracy of the simulation even further (SCP vs. DEF vs. WRF). Likewise, the

599 land surface energy balance (Qh, Qle, and Qg) components across the entire suite of 19 ARM-

600 SGP sites are shown in Fig. 8, where improvement is seen across the board in terms of reducing

601 the RMSE and Bias. Overall, these results provide strong evidence that spinup and calibration

602 improves coupled forecasts across the entire NU-WRF domain, as well as the individual site

603 details shown in Figs. 4-6.

604 2) 18-19 JULY 2006

605 The other dry regime case study results are shown in Fig. 9 and Table 4. As the dry-

606 down has progressed over the period, there is a larger diurnal range in $2 \mathrm{~m}$ temperature observed

607 ( 20K) than the 14 July case $(\sim 13 \mathrm{~K})$, while the humidity ranges are comparable on 18 July but

608 reach a much drier condition on 19 July as the surface begins nears desiccation. On both days in

609 Fig. 9, the DEF simulation shows a more extreme dry bias now versus observations, as reflected

610 in Q2 and the surface Bowen ratio. Despite this, the calibration in SCP still produces consistent

611 improvement in heat and moisture states and fluxes, particularly on 18 July. $\beta_{\text {sfc }}$ on 19 July is

612 observed to be much higher than the previous day, and supports a sharp diurnal decrease in Q2

613 due to lack of surface evaporation (and is similar to the mixing diagram signature seen in the dry 
614 soils results of S09 and S11). Overall, the SPN simulation (not shown) produces the lowest T2 615 and Q2 errors, but as was the case for 14 July this occurs for the wrong reasons, as $\beta_{\text {sfc }}$ is vastly 616 underestimated while CPL remains close to the DEF results. That SCP doesn't match or improve Bsfc observations as well as the previous cases is

618 because the overall nature of the calibration is to correct the dry bias in Noah thereby increasing 619 the soil moisture and Qle. The calibration works well overall, but for extreme conditions like on 62019 July the DEF simulation just so happens to produce better $\beta_{\text {sfc }}$ due to its inherent dry bias.

621 The limits of calibrating the spinup are also evident here, as the shift due to higher initial soil 622 moisture is felt in the coupled simulation to the degree of the shift in DEF to SCP curves, and 623 suggests there is still significant uncertainty and limitations in LSM physics that prevent even a 624 detailed calibration of large parameter sets from improving upon. 3) 16-17 JUNE 2007

The wet regime cases show a vastly different signature in the mixing diagrams that is 627 reflective of much higher evaporation rates at the surface and limited PBL growth and 628 entrainment above. Fig. 10 and Table 5 show that the DEF simulations generally perform well 629 relative to observations in terms of T2 and Q2 evolution, and that there actually is some 630 degradation in results after calibration on 16 June (note that the calibration performed for these 631 cases was appropriately based on the 1 May- 1 September 2007 period). The 632 degradation/improvement seen in T2 and Q2 in the SCP simulation on June 16/17 is due to the 633 DEF simulation being too wet/dry on these days, and due to the dry bias correcting nature of the 634 calibration has a positive impact only on the day when an initial dry bias exists. 
637 metrics. The calibration does improve $\beta_{\text {sfc }}$ in SCP over DEF and very close to observations, as 638 designed by the calibration. There is not any translation of this improvement to the PBL fluxes 639 or $2 \mathrm{~m}$ states, however. This is consistent with the results of S12, who showed that the impact of 640 a particular LSM is dampened during wet regimes when the PBL scheme and atmosphere-

641 dominated regime takes over. It can also be summarized that when the LSM and coupled model 642 perform well (as 16 June MAE, RMSE, Bias, and N-S metric suggest), there is little to be gained 643 in calibrating large sets of parameters because the inherent predictability in the system has 644 already been maximized.

645 4) 19-20 JUNE 2007

646 At the end of the wet regime, much poorer performance is seen in both the DEF and SCP 647 simulations (Fig. 11 and Table 6) in terms of the diurnal evolution of T2 and Q2. Particularly on 64819 June when DEF has a wet bias in the morning, there is degradation across all metrics (with 649 the exception of the Q2 bias), which is again consistent with the calibration attempt to correct the 650 overall dry bias that is not evident on this particular day. As also evident from the comparisons 651 of all the case studies thus far, there is a noticeable shift on 19 June to a very wet regime (high 652 Q2) that is reflective of frequent precipitation events in the days prior (including the passage of a 653 MCS over the study region).

20 June is much similar to 16-17 June in that there is very little impact of calibration on

655 the results. Overall, the wet regime is dominated by low $\beta_{\text {sfc }}$ and relatively high Qle, along with 656 lower net radiation (due to clouds and precipitation), and reduced PBLH, entrainment, and 657 diurnal cycles of T2 and Q2. This makes the potential impact from LSM adjustments (such as 658 calibration, spinup and initialization approaches) on the coupled system much lower than in the 659 dry regime. In addition, the attempt of calibration to systematically reduce inherent LSM biases 
660 works least well for the extremes of regimes (e.g. just after frequent rainfall; end of a severe dry-

661 down) as opposed to the more benign, moderate, and transitional periods (as reflected in the

662 overall offline and domain-average results presented above).

663 c. Period of Calibration

664

The second part of this analysis addresses the question of 'what is the impact of the

665 period of calibration on coupled predictions?'. The 2006 case studies above were performed

666 using parameters calibrated during summer 2006 period, and the 2007 cases with parameters

667 calibrated during 2007. For broader applicability of this methodology, it is important to address

668 the impact of data availability and limitations on the calibration. For example, if observed fluxes

669 are only available for a limited time, certain year, or season (as is often the case for field

670 experiments) that does not coincide with the forecast period of interest there likely will not be as

671 optimal results seen in the offline calibration or coupled simulations.

672 Table 7 lists the experiments conducted to determine the impact of having observations

673 only during dry, wet, or average years, or having all three years available. These simulations are

674 each conducted using calibrated parameters in the spinup and during the coupled run, and

675 therefore C06 is identical to SCP in Figs. 4 and 9, C07 is the same as SCP in Figs. 10 and 11, and

676 DEF is the same as in all previous analyses.

677 The land surface energy balance components for the 2008 offline calibration are shown in

678 Fig. 12. Improvement in RMSE of Qle and Qh is seen at all but 3 and 5 sites, respectively, but to

679 a much lesser degree overall ( 5-10 Wm-2) than was seen in 2006 and 2007. Likewise, the

680 impact of calibration on the diurnal cycle fluxes is very small, particularly for Qle (which is

681 already simulated quite well by default), although Qg shows more impact and degradation during

682 daytime than either 2006 or 2007. 
The results for the offline calibration using all three years of data (2006, 2007, and 2008)

684

685

686

687

688

689

690

691

692

693

694

695

696

697

698

699

700

701

702

703

704

705 combined are then shown in Fig. 13. Once again, the GA algorithm performs well in improving the flux components nearly at nearly all sites (with the exception of only 2 in Qle and Qh), and overall improvement in RMSE is on the order of 15-20 Wm-2. The diurnal cycles show marked improvement in both Qle and Qh, nearly matching observations in each and lowering the daytime magnitude of each. Some degradation is seen in Qg where it is overestimated during the daytime, therefore compensating somewhat for the reduction in Qh and Qle.

The 14 July 2006 case study results for the suite of simulations with different year calibrations are shown in Figs. 14-16 and Table 8. DEF and C06 are the same as in Fig. 4, but what is now evident is the spread in results introduced by different calibration periods. C07 performs nearly as well as C06 despite that this is a 2006 case (Fig. 14), with both the T2 and Q2 evolution and error metrics almost identical (Table 8). The similarity of C06 and C07 follow in the PBL budget (Fig. 15) and EF vs. PBLH analysis (Fig. 16) as well. The worst performing simulation by far is that with the calibrated parameters from the average year (C08), which is too dry and significantly overestimates $\beta_{\text {sfc }}$ as a result (low Qle, high Qh). This translates into entrainment and total PBL budgets that are too large in Fig. 15, and reflected in low EF and large PBL growth in Fig. 16. The calibration using all three years of data (C678) generally performs well, but less so than either C06 or C07 which is as expected given the performance and weighting of the individual years.

These results suggest that calibration using observations that capture the dry and wet sides of the soil moisture distribution is critical to coupled prediction improvement. Similar results are also seen for the 18-19 July 2006 case study (ranked as C06, C07, C678, C08 from most to least improvement), and similar mixed/limited impacts seen in the 2007 cases. This may 
706 be due to the calibration correction of the Noah dry bias through the new parameter sets, but only

707 is possible during extreme conditions when the model biases are significant. It is also an

708 important result that using 'average' calibrated parameters (C08) during an extreme condition

709 actually degrades the coupled results due to a now slightly drier soil moisture condition and less

710 evaporative Noah overall (thus enhancing the bias).

\section{1 d. Uncertainty Propagation}

An interesting question that is inherent in parameter estimation studies is how to quantify

713 the sensitivity of LSMs to calibrated parameter sets generated by algorithms such as GA. In a

714 similar vein, tools have been developed for LIS-OPT/UE that can be extended to quantify how

715 uncertainty in LSM spinups and initial conditions is translated to coupled forecasts. To address

716 this issue, an additional suite of simulations was conducted using a simple Monte Carlo

717 simulation (MC-SIM) sampling algorithm implemented in LIS-OPT/UE in order to propagate

718 uncertainty from inputs (e.g. soil, vegetation, and general parameters) to model outputs (e.g.,

719 offline spinup, coupled prediction). As such, this algorithm allows for an assessment of LSM

720 uncertainty, and can be used to gauge the relative sensitivity of the coupled system to LSM

721 inputs. A small sample size (5) was applied given that WRF does not have a true ensemble

722 mode, and essentially requires independent integrations for each set. As in Kumar et al. (2012),

723 uniform distributions were applied to all parameters given the limits of the ranges also based on

724 Kumar et al. (2012). The result is a sense of the spread in simulations prior to calibration.

725 Figure 17 shows the results of the DEF and C06 simulations (as in Fig. 14) for the 14

726 July 2006 case, along with the simulations using the 5 parameter sets sampled with MC-SIM

727 (used in both the spinup and coupled run, as for C06). The large spread in results (shaded area)

728 highlights the importance of LSM parameter sets in the coupled forecast of heat and moisture 
729

730

731

732

733

734

735

736

737

738

739

740

741

742 in coupled forecasts.

states and fluxes. That MC-SIM randomly sampled these sets suggests the full spread, using physically reasonable bounds on parameter values as was done here, could actually be much larger than shown here as well. Nearly all of the MC-SIM simulations are on the dry side of observations, an indication of the dry bias in the Noah model that is only circumvented when using the full C06 calibration with observations. The fluxes in MC-SIM vary quite a bit as well, where $\beta_{\text {sfc }}$ ranges from $0.733-4.960$ and large errors versus observed are carried into the entrainment and ratio components.

Overall, these results show the potential uncertainty in LSM parameter specification and substantial impact on the coupled system. The next phase of this research will further explore uncertainty propagation, and quantify how the spread in predictions is narrowed after incorporating observations into the system via calibration. For this task, LIS-OPT/UE has been augmented to include recent algorithmic advances in Markov chain Monte Carlo (MCMC) and will be used to evaluate trade-offs in observation quality and frequency on reducing uncertainty

5. Discussion

The questions addressed in this study of improving coupled prediction using LSM

745 calibration have shed light on the following issues: 1) what to calibrate, 2) how to calibrate, and 746 3) when to calibrate. Because fluxes are the most important aspect of LSMs for atmospheric 747 models, the largest impact will be seen in calibrating a LSM to Qle and Qh observations. In the 748 approach presented here, in contrast to Santanello et al. 2007, we calibrate only fluxes and 749 therefore, soil states such as moisture and temperature are by-products without observational 750 constraints. Current and future missions such as SMOS and SMAP will provide soil moisture 751 state observations that can be used to calibrate soil hydraulic properties as shown in Santanello et 
752 al, etc. However, based on the work presented here, and given the interaction between the soil

753 hydraulics and the canopy conductance, it will be most beneficial to land-atmosphere prediction

754 if both state and flux measurements can be used simultaneously to calibrate LSM parameters.

755 In terms of how to calibrate, it is not so much the algorithm choice (e.g. similar

756 performance has been seen in LIS-OPT/UE intercomparisons of the three methods therein;

757 Harrison et al. 2012) so much as the parameter sets and mapping approach that is employed that 758 is important for coupled prediction. NU-WRF is fully 3-D and communicates horizontally 759 between grid cells through the atmospheric flow. This is in contrast to LIS and most LSMs, 760 which operate in 1-D. This makes it particularly important that parameter calibration and 761 assignment be considered carefully for coupled studies. The approach performed in this study 762 entailed the assignment of soil, vegetation, and general parameter types, followed by averaging 763 across observation sites for like classes of each and assignment to the full domain. With the 764 exception of a few sites in the offline calibration results, this approach seemed to work well 765 overall as evidenced by the independent assessment of 214 locations of T2 and Q2 performance 766 in the coupled run. A next step in this regard is to investigate the classification at those ARM767 SGP sites that degraded after calibration to see if the soil type and land cover representation at 768 those flux towers was represented accurately by the datasets (STATSGO and UMD) chosen for 769 this study. The final question of when to calibrate has been addressed directly as well, and found 771 some interesting results that should be taken into account in future studies. That the calibration 772 in the wet regime worked nearly as well as the dry regime parameters suggests that in order to 773 improve simulations during extremes, the calibration should at least include a period of extreme 774 soil moisture conditions. Clearly, this is not a one-size-fits-all approach, and depends on the 
775 seasonality of a particular location/climate regime, but also suggests that the model physics be

776 tested outside of 'average' conditions in order to maximize LSM improvement due to calibration.

777 (i.e. to capture wings of the distribution (dry-downs and wet-ups) and model biases). There are

778 many more experiments that could be performed in terms of period sensitivity (e.g. seasonal,

779 application to average condition coupled cases, etc.) that will be a part of future research.

780 Another issue rarely addressed in studies of LSM calibration is that of the physical

781 meaningfulness of the calibrated parameter values. It is important to consider what the

782 calibrated values look like and actually represent, relative to the default lookup tables.

783 Santanello et al. (2007) was successful in achieving both goals of reducing model bias and

784 maintaining parameter realism amongst soil hydraulic properties through the use of pedotransfer

785 functions. Here, the parameter set is large such that it remains difficult to ensure or even

786 evaluate inter-parameter consistency and applicability to real world (or measured) properties, not

787 to mention that not all parameters in Noah LSM are observable. For most calibration studies, the 788 ends (i.e. improved flux output) justify the means (i.e. limited parameter realism). However, we 789 can still take a closer look at the evaporative physics in Noah and two of the commonly modified 790 and 'tuned' parameters in previous studies.

791

The FXEXP parameter is the exponent for bare soil evaporation in Noah, which is a

792 function of soil moisture and vegetation amount. Lower values of FXEXP increase the bare soil 793 component of Qle for a given soil moisture/vegetation amount, and the default value is 2.0.

794 Table 9 shows the calibrated values from the different period experiments, and there is a definite 795 downward shift in FXEXP due to calibration towards 1.0. In fact, Santanello et al. (2007) 796 modified the FXEXP parameter in their study to be 1.0, due to the semi-arid region and inability 
797 of Noah to produce enough Qle. The calibration here has acted in the same manner in order to 798 increase Qle to match observations.

799 The other parameter of interest is part of the evaporative/flux calculations in Noah. CZIL 800 is the Zilitinkevich coefficient relating surface fluxes to the roughness length for heat $\left(Z_{o h}\right)$ and 801 the exchange coefficient $\left(C_{h}\right)$. There has been recent work in Noah model development to 802 modify this from its default value of 0.1 to something higher or lower dependent on vegetation 803 coverage (e.g. Mitchell et al. 2004, LeMone et al. 2010, Trier et al. 2011). Higher values of 804 CZIL decrease $Z_{o h}, C_{h}$, and flux magnitudes overall. Table 9 shows the values of CZIL from 805 DEF lookup table of Noah along with calibrated values from different periods and the prior study 806 estimates. The value has been raised to 0.6 in the calibrations that perform best (C06, C07, 807 C678) versus 0.1 in the DEF and the poor calibration of C08. These results are consistent with tests of the Noah model over the ARM-SGP domain by 809 LeMone et al. (2010) who found that CZIL should be larger in this region. The SPN vs. CPL 810 results here also support those of Trier et al. (2008) in terms of consistency in calibrated 811 parameter sets, and suggest that the results of Trier et al. (2011) would have shown even greater 812 sensitivity of land-PBL coupling to CZIL if the same modified values were used both in the 813 spinup and coupled runs (their CZIL modifications were applied to the coupled run only).

814 Overall, the calibrated values of both CZIL and FXEXP appear to be physically consistent with 815 previous studies' manual tuning of parameters, and while they by no means guarantee the same 816 for the other 27 parameters involved at least suggest some physical consistency and model 817 improvement that produces the right answer for the right reasons.

\section{6. Conclusions}


This study examines the impact of LSM spinup and calibration on the land-PBL coupling

820 in regional model forecasts. Sensitivities to dry/wet regimes, period of calibration, and

821 parameter sets were quantified using diagnostics of land-atmosphere coupling and applied to the

822 NU-WRF coupled modeling system. Key findings from this work include the following:

823 - Offline calibration using a surface flux network is successful in reducing LSM biases and

824 improving diurnal cycles of Qle and Qh.

825 - Calibrated parameter sets can improve fluxes and states during both dry and wet regimes, and

826 extend their impact to PBL fluxes and ambient weather (T2 and Q2).

827 - Largest impacts of offline calibration on coupled runs are seen during the dry regime when the

828 turbulent fluxes are larger and atmospheric and precipitation forcing is weak.

829 - A calibrated spinup by itself can produce more accurate temperature and humidity forecasts, 830 regardless of the parameter sets used in the coupled simulation; though consistency in parameter

831 sets between spinup and coupled runs is critical to improving performance and maintaining

832 physical consistency in both states and fluxes

833 - Including periods of dry and/or wet extremes for a particular region in the calibration process

834 leads to better offline and coupled simulations.

835 - Significant variability in hydrometeorological prediction can result from LSM parameter 836 uncertainty, but can be reduced using observations and calibration approaches.

837 These experiments were also designed as a prototype testbed for future satellite missions

838 (e.g. SMAP). Using LIS-OPT/UE, the tradeoffs of data availability vs. accuracy and uncertainty 839 in prediction can be quantified systematically. The classification strategy relates to the spatial

840 tradeoffs of satellite sensors, while the period of calibration relates to the satellite overpass return 841 time. In the future, simultaneous development of Earth science technologies (e.g. microwave 
842 soil moisture sensors) and methodologies (e.g. thermal evapotranspiration retrievals) will warrant 843 the LIS-OPT/UE approach in assessing the impact of observations on coupled forecasts, for both 844 calibration and data assimilation studies alike.

845 Acknowledgements. This work was supported by the NASA's Advanced Information System 846 Technology program (AIST) and the Earth Science Technology Office (ESTO). The NU-WRF 847 team was also instrumental in providing support related to LIS-WRF coupling and a stable and 848 updated version of the coupled system. The data for the MET analysis are from the Research 849 Data Archive (RDA), which is maintained by the Computational and Information Systems 850 Laboratory (CISL) at the National Center for Atmospheric Research (NCAR). The original data 851 are available from the RDA (http://dss.ucar.edu) in dataset number ds337.0. 


\section{References}

Anthes, R.A., and T.T. Warner, 1978: Development of Hydrodynamic Models Suitable for Air Pollution and Other Mesometerological Studies. Mon. Wea. Rev., 106, 1045-1078.

Betts, A.K., 1992: FIFE atmospheric boundary layer budget methods. J. Geophys. Res., 97, 18523-18532.

Betts, A. K., 2009: Land-surface-atmosphere coupling in observations and models. J. Adv. Model Earth Syst., Vol. 1, Art. \#4, 18 pp., doi: 10.3894/JAMES.2009.1.4.

Case, J. L., W. L. Crosson, S. V. Kumar, W. M. Lapenta, C. D. Peters-Lidard, 2008: Impacts of High-Resolution Land Surface Initialization on Regional Sensible Weather Forecasts from the WRF Model. J. Hydrometeor, 9, 1249-1266.

Case, J. L., S. V. Kumar, J. Srikishen, G. J. Jedlovec, 2011: Improving Numerical Weather Predictions of Summertime Precipitation over the Southeastern United States through a HighResolution Initialization of the Surface State. Wea. Forecasting, 26, 785-807.

Chen, F., and K. Mitchell, 1999: Using GEWEX/ISLSCP forcing data to simulate global soil moisture fields and hydrological cycle for 1987-1988. J. Meteor. Soc. Japan, 77, 167-182.

Chen, F., Manning, K.W., Lemone, M.A., Trier, S.B., Alfieri, J.G., 2007: Description and evaluation of the characteristics of the NCAR high-resolution land data assimilation system. Journal of Applied Meteorology and Climatology, 46, 694-713, 10.1175/JAM2463.1.

Chin, M., R. B. Rood, S.-J. Lin, J. F. Muller, and A. M. Thomspon, 2000: Atmospheric sulfur cycle in the global model GOCART: Model description and global properties. J. Geophys. Res., 105, 24,671-24,687.

Cosgrove, B. A., et al., 2003: Land surface model spin-up behavior in the North American Land Data Assimilation System (NLDAS), J. Geophys. Res., 108, 8845, doi:10.1029/2002JD003316.

de Goncalves, L. G. G., W. J. Shuttleworth, E. J. Burke, P. Houser, D. L. Toll, M. Rodell, and K. Arsenault, 2006: Toward a South America Land Data Assimilation System: Aspects of land surface model spin-up using the Simplified Simple Biosphere, J. Geophys. Res., 111, D17110, doi:10.1029/2005JD006297.

Di Giuseppe, Francesca, Davide Cesari, Giovanni Bonafé, 2011: Soil Initialization Strategy for Use in Limited-Area Weather Prediction Systems. Mon. Wea. Rev., 139, 1844-1860.

Dirmeyer, P., R. Koster, Z. Guo, 2006: Do Global Models Properly Represent the Feedback Between Land and Atmosphere?. J. Hydrometeorol., 7, Issue 6. DOI:10.1175/JHM532.1.

Duan, Q., V. Gupta, and S. Sorooshian, 1993: A shuffled complex evolution approach for effective and efficient global minimization. J. Optim. Theory. Appl., 76(3), 501-521. 
Ek M. B., K. E. Mitchell, Y. Lin, E. Rogers, P. Grunmann, V. Koren, G. Gayno, and J. D. Tarpley, 2003: Implementation of Noah land surface model advances in the National Centers for Environmental Prediction operational mesoscale Eta Model. J. Geophys. Res., 108, 8851, doi:10.1029/2002JD003296.

Feddes, R.A., M. Menenti, P. Kabat, and W.G.M. Bastiaanssen, 2003: Is large-scale inverse modeling of unsaturated flow with areal average evaporation and surface soil moisture as estimated from remote-sensing feasible. J. Hydrol., 143(1-2), 125-152.

Gilks, W.R., S. Richardson, and D.J. Spiegelhalter, 1996: Introducing Markov chain Monte Carlo”, In Markov chain Monte Carlo in Practice, Edited by W.R. Gilks, S. Richardson, and D.J. Spiegelhalter, Chapman and Hall.

Gupta, H.V., L.A. Bastidas, S. Sorooshian, W.J. Shuttleworth, and Z.L. Yang, 1999: Parameter estimation of a land-surface scheme using multicriteria methods. J. Geophys. Res., 104(D16), 19,491-19,503.

Gutmann, E.D., and E.E. Small, 2005: The effect of soil hydraulic properties vs. soil texture in land surface models. Geophys. Res. Let., 32(2), L02402, doi:10.1029/2004GL021843.

Hansen, M. C., Defries, R. S., Townshend, J. R. G., \& Sohlberg, R., 2000: Global land cover classification at $1 \mathrm{~km}$ spatial resolution using a classification tree approach. International Journal of Remote Sensing, 21, 1331-1364.

Harrison, K.W., S.V. Kumar, C.D. Peters-Lidard and J.A. Santanello, 2012: Reducing soil moisture modeling uncertainty with remote sensing, Water Resources Res., submitted.

Hess, R., 2001: Assimilation of screen level observations by variational soil moisture analysis. Meteor. \& Atmos. Phys., 77(1-4), 145-154.

Hogue, T. S., L. Bastidas, H. Gupta, S. Sorooshian, K. Mitchell, and W. Emmerich, 2005:

Evaluation and Transferability of the Noah Land Surface Model in Semiarid Environments. $J$. Hydrometeorol., 6, 68-84.

Holland, J., 1975: Adaptation in Natural and Artificial Systems, University of Michigan Press, Ann Arbor, Michigan.

Holt, T., Niyogi, D., Chen, F., Manning, K.W., Lemone, M.A., 2006: Effect of land-atmosphere interactions on the IHOP 24-25 May 2002 convection case. Monthly Weather Review, 134, 113133, 10.1175/MWR3057.1.

Hong, S.Y., Y. Noh, and J. Dudhia, 2006: A New Vertical Diffusion Package with an Explicit Treatment of Entrainment Processes. Mon. Wea. Rev., 134, 2318-2341.

Hurk, B.J.J.M. van den and E.M. Blyth, 2008: WATCH/LoCo workshop report. 
GEWEX Newsletter, 12-14.

Hurk, B. J. J. M. can den, M. Best, P. Dirmeyer, A. Pitman, J. Polcher, J. Santanello, Jr. 2011: Acceleration of Land Surface Model Development over a Decade of Glass. Bull. Amer. Meteor. Soc., 92, 1593-1600.

Kato, H., M. Rodell, F. Beyrich, H. Cleugh, E. van Gorsel, H. Liu, and T.P. Meyers, 2007: Sensitivity of Land Surface Simulations to Model Physics, Parameters, and Forcings, at Four CEOP Sites, J. Meteor. Soc. Japan, 85A, 187-204.

Koster R. D., Coauthors, 2004: Regions of strong coupling between soil moisture and precipitation. Science, 306, 1138-1140.

Koster, R. D., S. Mahanama, T. Yamada, G. Balsamo, A.A. Berg, M. Boisserie, P. Dirmeyer, F. Doblas-Reyes, G. Drewitt, C.T. Gordon, Z. Guo, J.H. Jeong, D.M. Lawrence, W.-S. Lee, Z. Li, L. Luo, S. Maleyshev, W.J. Merryfield, S.I. Seneviratne, T. Stanelle, B.J.J.M. van den Hurk, F. Vitart and E.F. Wood, 2010: Contribution of land surface initialization to subseasonal forecast skill: First results from a multi-model experiment, Geophys. Res. Lett., 37, L02402, doi:10.1029/2009GL041677.

Kumar, S. V., C. D. Peters-Lidard, Y. Tian, P. R. Houser, J. Geiger, S. Olden, L. Lighty, J. L. Eastman, B. Doty, P. Dirmeyer, J. Adams, K. Mitchell, E. F. Wood and J. Sheffield, 2006: Land Information System - An Interoperable Framework for High Resolution Land Surface Modeling. Environmental Modelling \& Software, Vol. 21, 1402-1415.

Kumar, S. V., C. D. Peters-Lidard, J. L. Eastman, and W.-K. Tao, 2008: An integrated high resolution hydrometeorological modeling testbed using LIS and WRF. Environmental Modelling and Software, 23, 169-181.

Kumar, S., R. H. Reichle, K. W. Harrison, C. D. Peters-Lidard, S. Yatheendradas, and J. A. Santanello, 2012a: A comparison of methods for a priori bias correction in soil moisture data assimilation.Water Resour. Res., doi:10.1029/2010WR010261, in press.

Kumar, S. V., C. D. Peters-Lidard, J. A. Santanello, K. Harrison, Y. Liu, and M. Shaw, 2012b: Land surface Verification Toolkit (LVT) - A generalized framework for land surface model evaluation. Geosci. Model Dev., in press.

LeMone, Margaret A., Fei Chen, Mukul Tewari, Jimy Dudhia, Bart Geerts, Qun Miao, Richard L. Coulter, Robert L. Grossman, 2010: Simulating the IHOP_2002 Fair-Weather CBL with the WRF-ARW-Noah Modeling System. Part I: Surface Fluxes and CBL Structure and Evolution along the Eastern Track. Mon. Wea. Rev., 138, 722-744.

Levenberg, K., 1944: A method for the solution of certain non-linear problems in least squares. The Quarterly of Applied Mathematics, 2, 164-168. 
Liu, Y., L.A. Bastidas, H.V. Gupta, and S. Sorooshian, 2003: Impacts of a parameterization deficiency on offline and coupled land surface model simulations. J. Hydrometeor., 4(5), 901914.

Liu, Y., H.V. Gupta, S. Sorooshian, L.A. Bastidas, and W.J. Shuttleworth, 2004: Exploring parameter sensitivities of the land surface using a locally coupled land-atmosphere model. $J$. Geophys. Res. Atmos., 109(D21), D21101, doi: 10.1029/2004JD004730.

Liu, Y., H.V. Gupta, S. Sorooshian, L.A. Bastidas, and W.J. Shuttleworth, 2005: Constraining land surface and atmospheric parameters of a locally coupled model using observational data. $J$. Hydrometor., 6(2), 156-172.

Marquardt, D., 1963: An algorithm for least-squares estimation of nonlinear parameters. SIAM Journal on Applied Mathematics, 11, 431-441.

Matsui, T., W. Tao, H. Masunaga, C. D. Kummerow, W. S. Olson, N. Teruyuki, M. Sekiguchi, M. Chou, T. Y. Nakajima, X. Li, J. Chern, J. J. Shi, X. Zeng, D. J. Posselt, K. Suzuki, 2009: Goddard Satellite Data Simulation Unit: Multi-Sensor Satellite Simulators to Support AerosolCloud-Precipitation Satellite Missions, Eos Trans. AGU, 90(52), Fall Meet. Suppl., Abstract A21D-0268

Mesinger, F., and Coauthors, 2006: North American Regional Reanalysis. Bull. Amer. Meteor. Soc., 87, 343-360.

Miller, D. and R. White, 1998. A conterminous United States multilayer soil characteristics dataset for regional climate and hydrology modeling. Earth Interactions, 2, 1-26.

Mitchell, K. E., et al., 2004: The multi-institution North American Land Data Assimilation System (NLDAS): Utilizing multiple GCIP products and partners in a continental distributed hydrological modeling system. J. Geophys. Res., 109, D07S90,doi:10.1029/2003JD003823.

Nash, J. E. and J. V. Sutcliffe, 1970: River flow forecasting through conceptual models part I A discussion of principles. Journal of Hydrology, 10 (3), 282-290.

Peters-Lidard, C. D., D. M. Mocko, J. A. Santanello, M. Tischler, M. S. Moran, M. Garcia, and Y. Wu, 2008: The role of precipitation uncertainty for soil property estimation using soil moisture retrievals in a semi-arid environment. Water Resour. Res., 44, W05S18.

Peters-Lidard, C. D., P. R. Houser, Y. Tian, S. V. Kumar, J. Geiger, S. Olden, L. Lighty, B. Doty, P. Dirmeyer, J. Adams, K. Mitchell, E. F. Wood and J. Sheffield, 2007: High-performance Earth system modeling with NASA/GSFC's Land Information System. Innovations in Systems and Software Engineering, Vol. 3(3), 157-165.

Reichle, R.H., S.V. Kumar, S.P.P. Mahanama, R.D. Koster and Q. Liu, 2010: Assimilation of satellite-derived skin temperature observations into land surface models. J. Hydrometeorol., 11,1103-1122,doi:10.1175/2010JHM1262.1. 
Robock, A., L. Luo, E.F. Wood, F. Wen, K.E. Mitchell, P.R. Houser, J.C. Schaake, D. Lohmann, B. Cosgrove, J. Sheffield, Q. Duan, R.W. Higgins, R.T. Pinker, J.D. Tarpley, J.B. Basara, and K.C. Crawford, 2003: Evaluation of the North American Land Data Assimilation System over the southern Great Plains during the warm season. J. Geophys. Res., 108(D22), 8846, doi:10.1029/2002JD003245.

Rodell, M., P.R. Houser, U. Jambor, J. Gottschalck, K. Mitchell, C.-J. Meng, K. Arsenault, B. Cosgrove, J. Radakovich, M. Bosilovich, J.K. Entin, J.P. Walker, D. Lohmann, and D. Toll, 2004: The Global Land Data Assimilation System. Bull. Amer. Meteor. Soc., 85(3), 381-394, 2004.

Rodell, M., P.R. Houser, A.A. Berg, and J.S. Famiglietti, 2005: Evaluation of 10 Methods for Initializing a Land Surface Model. J. Hydromet., 6(2), 146-155

Santanello, J. A., C. Peters-Lidard, M. Garcia, D. Mocko, M. Tischler, M. S. Moran, and D. P Thoma, 2007: Using Remotely-Sensed Estimates of Soil Moisture to Infer Spatially Distributed Soil Hydraulic Properties. Rem. Sens. Env., 110, 79-97.

Santanello, J. A., Christa D. Peters-Lidard, Sujay V. Kumar, Charles Alonge, Wei-Kuo Tao, 2009: A Modeling and Observational Framework for Diagnosing Local Land-Atmosphere Coupling on Diurnal Time Scales. J. Hydrometeor, 10, 577-599.

Santanello, J. A., C. D. Peters-Lidard, and S. V. Kumar, 2011a: Diagnosing the Sensitivity of Local Land-Atmosphere Coupling via the Soil Moisture-Boundary Layer Interaction. $J$. Hydrometeor, 12, 766-786.

Santanello, J. A., 2011b: Results from Local Land-Atmosphere Coupling (LoCo) Project. GEWEX Newsletter, 21(4), 7-9.

Santanello, J. A., C. Peters-Lidard, A. Kennedy, and S. Kumar, 2012: Diagnosing the Nature of Land-Atmosphere Coupling During the 2006-7 Dry/Wet Extremes in the U. S. Southern Great Plains. J. Hydromet., under revision.

Seneviratne, S. I., T. Corti, E. L. Davin, M. Hirschi, E. B. Jaeger, I. Lehner,, B Orlowsky, A. J. Teuling, 2010: Investigating soil moisture-climate interactions in a changing climate: A review. Earth-Science Rev., 99, 125-161.

Skamarock, W. C., J. B. Klemp, J. Dudhia, D. O. Gill, D. M. Barker, W. Wang and J. G. Powers, 2005: A Description of the Advanced Research WRF Version 2, NCAR Tech Note, NCAR/TN468+STR, 88 pp. [Available from UCAR Communications, P.O. Box 3000, Boulder, CO, 80307; on-line at: http://box.mmm.ucar.edu/wrf/users/docs/arw_v2.pdf]

Soet, M., and J.N.M. Stricker, 2003: Functional behaviour of pedotransfer functions in soil water flow simulation. Hydro. Proc., 17(8), 1659-1670. 
ter Braak, C.J.F., 2006: A Markov chain Monte Carlo version of the genetic algorithm differential evolution: easy Bayesian computing for real parameter spaces. Stat Comput, 16, 239249.

Trier, S. B., F. Chen, K. W. Manning, M. A. LeMone, C. A. Davis, 2008: Sensitivity of the PBL and Precipitation in 12-Day Simulations of Warm-Season Convection Using Different Land Surface Models and Soil Wetness Conditions. Mon. Wea. Rev., 136, 2321-2343.

Trier, S. B., M. A. LeMone, F. Chen, K. W. Manning, 2011: Effects of Surface Heat and Moisture Exchange on ARW-WRF Warm-Season Precipitation Forecasts over the Central United States. Wea. Forecasting, 26, 3-25.

Troen, I., and L. Mahrt, 1986: A simple model of the atmospheric boundary layer: Sensitivity to surface evaporation. Bound.-Layer Meteor., 37, 129-148..

U.S. Department of Agriculture, Natural Resources Conservation Service, 1994. State Soil Geographic (STATSGO) database for Arizona. State College, PA: Penn State University Earth Systems Science Center. http://www.essc.psu.edu/soil_info/index.cgi?soil_data\&statsgo

van Heerwaarden, C. C., Vilà-Guerau de Arellano, J., Moene, A. F. and Holtslag, A. A. M., 2009: Interactions between dry-air entrainment, surface evaporation and convective boundary-layer development. Quarterly Journal of the Royal Meteorological Society, 135, 1277-1291. doi: 10.1002/qj.431.

Wen, X., S. Lu, J. Jin, 2012: Integrating Remote Sensing Data with WRF for Improved Simulations of Oasis Effects on Local Weather Processes over an Arid Region in Northwestern China. J. Hydrometeor, 13, 573-587.

Xia, Y., Ek, M., Wei, H. and Meng, J., 2012: Comparative analysis of relationships between NLDAS-2 forcings and model outputs. Hydrol. Processes, 26, 467-474.

Yang, Z., Dickinson, R.E., Henderson-Sellers, A. and Pitman, A.J., 1995: Preliminary study of spin-up processes in land surface models with the first stage data of Project for Intercomparison of Land Surface Parameterization Schemes Phase 1(a). Journal of Geophysical Research 100, doi: 10.1029/95JD01076. issn: 0148-0227. 


\section{LIST OF TABLES}

Table 1: Minimum and maximum values of the Noah parameters used in the LIS-OPT experiments.

Table 2: Description of calibration approaches and parameter sets used in NU-WRF simulations.

Table 3: Error statistics for Fig.4, where the co-evolution of 2m-specific humidity (Q2) and temperature (T2) are from each simulation is evaluated against observations in time in terms of RMSE, MAE, Bias, and the Nash-Sutcliffe Efficiency (Nash and Sutcliffe, 1970).

Table 4ab: Error statistics from a) Fig. 9a and b) Fig. 9b for all four simulations.

Table 5ab: Error statistics from a) Fig. 10a and b) Fig. 10b for all four simulations.

Table 6ab: Error statistics from a) Fig. 11a and b) Fig. 11b for all four simulations.

Table 7: Description of calibration approaches and parameter sets used in NU-WRF simulations.

Table 8: Error statistics from Fig.14 for each of the simulations.

Table 9: Values of the Noah CZIL and FXEXP parameters used in each of the simulations and the CZIL studies of LeMone et al. (2008) and Trier et al. (2011). 


\section{LIST OF FIGURES}

Figure 1abc: Soil moisture $\left(\mathrm{m}^{3} \mathrm{~m}^{-3 *} 100\right)$ in the upper $0-10 \mathrm{~cm}$ layer valid at $00 \mathrm{Z}$ on 1 July a) 2006, b) 2007, and c) 2008 as simulated from a multi-year spinup of the Noah LSM with default parameter sets over the 500x500 1-km NU-WRF domain in the SGP, along with the ARM-SGP Lamont, OK (E13) and Plevna, KS (E4) sites.

Figure 2abc: Average RMSE (Wm-2) of calibration and default Noah simulations of hourly fluxes of a) latent, b) sensible, and c) soil (ground) heat flux at each of the ARM-SGP sites over the full 1 May - 1 September 2006 calibration period. Also shown are mean diurnal cycles across all ARM-SGP sites against observations.

Figure 3abc: Same as Fig. 3, but for the 1 May - 1 September 2007 calibration period.

Figure 4: Mixing diagram showing the diurnal co-evolution (7am-7pm) of 2m-specific humidity and 2m-potential temperature on 14 July 2006 at the E4 site for the set of default and calibrated NU-WRF simulations. Also shown are the Bowen and entrainment ratios as defined in S09 and described by the surface and entrainment vectors (dashed lines).

Figure 5: Full PBL budget components of surface, PBL, and total sensible and latent heat flux derived from the mixing diagram analysis in Fig. 4.

Figure 6: Daytime mean evaporative fraction versus PBL height for the simulations in Fig. 4.

Figure 7: Diurnal cycle and error statistics of 2-meter temperature (T2m) and humidity (Q2m) for the 14 July 2006 case and evaluated at 214 station pairs across the ARM-SGP domain for each 6-hourly increment.

Figure 8: Latent (Qle), sensible (Qh), and soil (Qg) heat flux RMSE and Bias statistics (Wm-2) on 14 July 2006 measured against the full set of ARM-SGP flux tower sites and evaluated hourly.

Figure 9ab: Mixing diagrams for the a) 18 and b) 19 July 2006 case study showing the DEF and SCP simulations against observations at the E4 site.

Figure 10ab: Mixing diagrams for the a) 16 and b) 17 June 2007 case study showing the DEF and SCP simulations against observations at the E4 site.

Figure 11ab: Mixing diagrams for the a) 19 and b) 20 June 2007 case study showing the DEF and SCP simulations against observations at the E4 site.

Figure 12abc: Same as Fig. 2, but for the 1 May - 1 September 2008 calibration period.

Figure 13abc: Same as Fig. 2, but for the combined 1 May - 1 September 2006, 2007, and 2008 calibration periods. 
Figure 14: Mixing diagrams for the 14 July 2006 case study showing the default (DEF) and suite of experiments using parameters calibrated during 2006 (C06), 2007 (C07), 2008 (C08), and all three years combined (C678), along with observations at the ARM-SGP E4 site.

Figure 15: Full PBL budget components of surface, PBL, and total sensible and latent heat flux derived from the mixing diagram analysis in Fig. 14.

Figure 16: Daytime mean evaporative fraction versus PBL height for the simulations in Fig. 14.

Figure 17: Mixing diagrams for the 14 July 2006 case study showing the default and suite of experiments using parameters calibrated during 2006 (C06) and 5 randomly sampled set generated from MC-SIM (MCSIM; shaded), along with observations at the ARM-SGP E4 site. 


\begin{tabular}{|c|c|c|}
\hline Noah Parameter & Minimum & Maximum \\
\hline SMCMAX & 0.30 & 0.50 \\
\hline PSISAT & 0.01 & 0.70 \\
\hline DKSAT (ms-1) & $0.05 \mathrm{E}-5$ & $3.00 \mathrm{E}-5$ \\
\hline DWSAT & $5.71 \mathrm{E}-6$ & $2.33 \mathrm{E}-5$ \\
\hline BEXP & 3 & 9 \\
\hline QUARTZ & 0.10 & 0.90 \\
\hline RSMIN (m) & 40 & 1000 \\
\hline RGL & 30 & 150 \\
\hline HS & 36 & 55 \\
\hline Z0 (m) & 0.01 & 0.99 \\
\hline LAI & 0.05 & 6.00 \\
\hline CFACTR & 0.10 & 2.00 \\
\hline CMCMAX (m) & $1.00 \mathrm{E}-4$ & $2.00 \mathrm{E}-3$ \\
\hline SBETA & -4.00 & -1.00 \\
\hline RSMAX (m) & 2000 & 10000 \\
\hline TOPT (K) & 293 & 303 \\
\hline REFDK & $5.00 \mathrm{E}-7$ & $3.00 \mathrm{E}-5$ \\
\hline FXEXP & 0.20 & 4.00 \\
\hline REFDT & 0.10 & 10.00 \\
\hline CZIL & 0.05 & 0.80 \\
\hline FRZK & 0.10 & 0.25 \\
\hline SNUP & 0.025 & 0.08 \\
\hline SMCREF & 0.00 & 0.50 \\
\hline SMCDRY & 0.00 & 0.15 \\
\hline SMCWLT & 0.00 & 0.15 \\
\hline F1 & -11 & 0 \\
\hline CSOIL & $1.26 \mathrm{E} 6$ & $3.56 \mathrm{E} 6$ \\
\hline SLOPE & 0.00 & 1.00 \\
\hline EMISS & 0.80 & 1.00 \\
\hline & & \\
\hline
\end{tabular}

Table 1: Minimum and maximum values of the Noah parameters used in the LIS-OPT experiments. 


\begin{tabular}{|c|c|c|c|c|}
\hline & Exp. & Description & $\begin{array}{c}\text { Spinup } \\
\text { Parameters }\end{array}$ & $\begin{array}{c}\text { Coupled } \\
\text { Parameters }\end{array}$ \\
\hline 1 & DEF & $\begin{array}{c}\text { Default run w/uncalibrated } \\
\text { params in LIS \& NU-WRF }\end{array}$ & Default & Default \\
\hline 2 & CPL & $\begin{array}{c}\text { Impact of calibrated } \\
\text { parameters in NU-WRF } \\
\text { ONLY }\end{array}$ & Default & Calibrated \\
\hline 3 & SPN & $\begin{array}{c}\text { Impact of calibrating LIS } \\
\text { spinup (ICs) ONLY }\end{array}$ & Calibrated & Default \\
\hline 4 & SCP & $\begin{array}{c}\text { Impact of full calibration } \\
\text { (LIS and NU-WRF) }\end{array}$ & Calibrated & Calibrated \\
\hline
\end{tabular}

Table 2: Description of calibration approaches and parameter sets used in NU-WRF simulations. 


\begin{tabular}{|cc|c|c|c|c|}
\cline { 3 - 6 } \multicolumn{1}{c|}{} & DEF & CPL & SPN & SCP \\
\hline Cum RMSE & 6288.60 & 6161.24 & 4665.10 & $\mathbf{5 3 1 4 . 0 7}$ \\
Cum MAE & & 5231.25 & 5181.39 & 4044.50 & $\mathbf{4 5 4 1 . 6 9}$ \\
\hline BIAS & Q2 & -6022.76 & -5743.49 & -3159.91 & $\mathbf{- 4 1 9 6 . 3 5}$ \\
BIAS & T2 & 4244.72 & 4458.54 & 3336.54 & $\mathbf{3 9 1 9 . 2 7}$ \\
\cline { 3 - 6 } N-S Efficiency & & -1.78 & -1.67 & -0.53 & $\mathbf{- 0 . 9 8}$ \\
\hline
\end{tabular}

Table 3: Error statistics for Fig.4, where the co-evolution of 2m-specific humidity (Q2) and temperature (T2) are from each simulation is evaluated against observations in time in terms of RMSE, MAE, Bias, and the Nash-Sutcliffe Efficiency (Nash and Sutcliffe, 1970). 


\begin{tabular}{|cc|c|c|c|c|}
\cline { 3 - 6 } \multicolumn{1}{c|}{} & DEF & CPL & SPN & SCP \\
\hline Cum RMSE & & 6018.59 & 5992.34 & 3977.58 & $\mathbf{5 0 8 6 . 3 2}$ \\
Cum MAE & & 4921.32 & 4992.19 & 3050.16 & $\mathbf{4 1 2 9 . 5 3}$ \\
\hline BIAS & $\mathbf{Q 2}$ & -7889.19 & -7859.74 & -5002.86 & $\mathbf{- 6 6 6 3 . 7 8}$ \\
BIAS & $\mathbf{T 2}$ & 1953.45 & 2124.63 & 818.18 & $\mathbf{1 5 9 5 . 2 7}$ \\
\cline { 3 - 6 } N-S Efficiency & & -0.385 & -0.373 & 0.394 & $\mathbf{0 . 0 1 1}$ \\
\hline
\end{tabular}

\begin{tabular}{|cc|c|c|c|c|}
\cline { 3 - 6 } \multicolumn{1}{c|}{} & DEF & CPL & SPN & SCP \\
\hline Cum RMSE & & 5916.36 & 5464.83 & 4031.29 & $\mathbf{5 1 1 6 . 1 4}$ \\
Cum MAE & & 4638.54 & 4450.96 & 2475.01 & $\mathbf{3 9 7 0 . 4 3}$ \\
\hline BIAS & $\mathbf{Q 2}$ & -6905.71 & -6541.11 & -3709.10 & $\mathbf{- 5 9 7 6 . 7 6}$ \\
BIAS & T2 & 2371.36 & 2360.82 & 416.55 & $\mathbf{1 9 6 4 . 0 9}$ \\
\cline { 3 - 6 } & & -0.128 & 0.038 & 0.476 & $\mathbf{0 . 1 5 7}$ \\
\hline
\end{tabular}

Table 4ab: Error statistics from a) Fig. 9a and b) Fig. 9b for all four simulations. 


\begin{tabular}{|cc|c|c|c|c|}
\cline { 3 - 6 } \multicolumn{1}{c|}{} & DEF & CPL & SPN & SCP \\
\hline Cum RMSE & & $\mathbf{1 3 8 0 . 6 9}$ & 1731.27 & 1539.36 & 1718.66 \\
Cum MAE & & $\mathbf{1 1 9 0 . 2 6}$ & 1421.29 & 1280.70 & 1386.36 \\
\hline BIAS & $\mathbf{Q 2}$ & $\mathbf{4 3 6 . 1 7}$ & -478.81 & 1283.31 & 938.37 \\
BIAS & $\mathbf{T 2}$ & $\mathbf{1 4 1 2 . 8 2}$ & 1920.64 & 1155.18 & 1485.82 \\
\cline { 3 - 6 } \\
N-S Efficiency & & $\mathbf{0 . 8 0 9}$ & 0.699 & 0.762 & 0.704 \\
\hline
\end{tabular}

\begin{tabular}{|cc|c|c|c|c|}
\cline { 3 - 6 } \multicolumn{1}{c|}{} & DEF & CPL & SPN & SCP \\
\hline Cum RMSE & & 1788.06 & 2480.89 & 1240.10 & $\mathbf{1 4 9 8 . 2 9}$ \\
Cum MAE & & 1644.65 & 2280.67 & 1119.14 & $\mathbf{1 3 3 8 . 2 5}$ \\
\hline BIAS & $\mathbf{Q 2}$ & -1761.03 & -2627.25 & -977.38 & $\mathbf{- 1 1 6 4 . 0 2}$ \\
BIAS & T2 & 1528.27 & 1934.09 & 1237.55 & $\mathbf{1 2 4 0 . 9 1}$ \\
\cline { 3 - 6 } N-S Efficiency & & 0.183 & -0.573 & 0.607 & $\mathbf{0 . 4 2 6}$ \\
\hline
\end{tabular}

Table 5ab: Error statistics from a) Fig. 10a and b) Fig. 10b for all four simulations. 


\begin{tabular}{|cc|c|c|c|c|}
\cline { 3 - 6 } \multicolumn{1}{c|}{} & DEF & CPL & SPN & SCP \\
\hline Cum RMSE & & $\mathbf{4 1 7 7 . 3 1}$ & 4963.27 & 4263.40 & 4611.42 \\
Cum MAE & & $\mathbf{3 5 0 1 . 5 1}$ & 4383.16 & 3576.48 & 3987.41 \\
\hline BIAS & $\mathbf{Q 2}$ & -257.51 & -1412.37 & 1159.99 & $\mathbf{1 4 2 . 8 1}$ \\
BIAS & $\mathbf{T 2}$ & $\mathbf{2 3 6 1 . 7 3}$ & 3213.09 & 2043.18 & 2811.18 \\
\cline { 3 - 6 } \\
\cline { 3 - 6 } N-S Efficiency & & $\mathbf{- 1 . 1 9 3}$ & -2.096 & -1.285 & -1.673 \\
\hline
\end{tabular}

\begin{tabular}{|cc|c|c|c|c|}
\cline { 3 - 6 } \multicolumn{1}{c|}{} & DEF & CPL & SPN & SCP \\
\hline Cum RMSE & & $\mathbf{1 5 9 8 . 9 3}$ & 1898.51 & 2301.55 & 1632.62 \\
Cum MAE & & $\mathbf{1 4 1 2 . 1 5}$ & 1708.75 & 2026.01 & 1497.77 \\
\hline BIAS & $\mathbf{Q 2}$ & -467.35 & -1119.43 & 2471.04 & $\mathbf{- 1 9 5 . 4 5}$ \\
BIAS & $\mathbf{T 2}$ & $\mathbf{1 3 7 3 . 5 5}$ & 1948.36 & 1144.36 & 1639.91 \\
\cline { 3 - 6 } N-S Efficiency & & $\mathbf{0 . 6 7 2}$ & 0.538 & 0.321 & 0.658 \\
\hline
\end{tabular}

Table 6ab: Error statistics from a) Fig. 11a and b) Fig. 11b for all four simulations. 


\begin{tabular}{|c|c|c|c|c|}
\hline & Exp. & Description & $\begin{array}{c}\text { Spinup } \\
\text { Parameters }\end{array}$ & $\begin{array}{c}\text { Coupled } \\
\text { Parameters }\end{array}$ \\
\hline 1 & DEF & $\begin{array}{c}\text { Default run } \\
\text { w/uncalibrated params }\end{array}$ & Default & Default \\
\hline 2 & C06 & $\begin{array}{c}\text { Impact of calibrating } \\
\text { during 2006 only }\end{array}$ & 2006 & 2006 \\
\hline 3 & $\mathbf{C 0 7}$ & $\begin{array}{c}\text { Impact of calibrating } \\
\text { during 2007 only }\end{array}$ & 2007 & 2007 \\
\hline 4 & $\mathbf{C 0 8}$ & $\begin{array}{c}\text { Impact of calibrating } \\
\text { during 2008 only }\end{array}$ & 2008 & 2008 \\
\hline 5 & $\mathbf{C 6 7 8}$ & $\begin{array}{c}\text { Impact of calibrating to } \\
\text { all three years combined }\end{array}$ & $2006-7-8$ & $2006-7-8$ \\
\hline
\end{tabular}

Table 7: Description of calibration approaches and parameter sets used in NU-WRF simulations. 


\begin{tabular}{|c|c|c|c|c|c|}
\cline { 2 - 6 } \multicolumn{1}{c|}{} & DEF & C07 & C08 & C06 & C678 \\
\hline \multirow{2}{*}{ Cum MAE } & 5231.25 & $\mathbf{4 5 3 8 . 3 2}$ & 5707.05 & $\mathbf{4 5 4 1 . 6 9}$ & 4630.35 \\
\cline { 2 - 6 } Cum RMSE & 6288.60 & $\mathbf{5 3 7 1 . 5 6}$ & 6851.72 & $\mathbf{5 3 1 4 . 0 7}$ & 5490.36 \\
\hline \multirow{2}{*}{ Q2 BIAS } & -6022.76 & $\mathbf{- 4 2 4 9 . 0 4}$ & -7044.01 & $\mathbf{- 4 1 9 6 . 3 5}$ & $\mathbf{- 4 4 9 2 . 1 1}$ \\
\cline { 2 - 6 } N-S Efficiency & $\mathbf{4} 244.73$ & $\mathbf{3 9 7 7 . 1 8}$ & 4370.09 & $\mathbf{3 9 1 9 . 2 7}$ & 3998.27 \\
\cline { 2 - 6 } & -1.782 & $\mathbf{- 1 . 0 3 0}$ & -2.303 & $\mathbf{- 0 . 9 8 7}$ & -1.121 \\
\hline
\end{tabular}

Table 8: Error statistics from Fig.14 for each of the simulations. 


\begin{tabular}{|c|c|c|c|c|c|c|c|}
\hline & DEF & C06 & C07 & C08 & C678 & $\begin{array}{c}\text { LeMone } \\
\text { et al. } \\
\mathbf{( 2 0 0 8 )}\end{array}$ & $\begin{array}{c}\text { Trier } \\
\text { et al. } \\
\mathbf{( 2 0 1 1}\end{array}$ \\
\hline FXEXP & 2 & 1.06 & 1.34 & 0.969 & 1.19 & - & - \\
\hline CZIL & 0.1 & 0.6 & 0.6 & 0.1 & 0.6 & 0.5 & $0.1-1.0$ \\
\hline
\end{tabular}

Table 9: Values of the Noah CZIL and FXEXP parameters used in each of the simulations and the CZIL studies of LeMone et al. (2008) and Trier et al. (2011). 